\title{
ANALYSIS OF THE MATHEMATICAL CORRELATION BETWEEN POST-SHARPED HOB AND WORM GEAR TOOTH SURFACE
}

\author{
József Ábel \\ PhD student, University of Miskolc, Institute of Mathematics, Department of Descriptive Geometry \\ 3515 Miskolc, Miskolc-Egyetemváros, e-mail: abel.jozsef16@gmail.com
}

\begin{abstract}
The production geometry development of the worm gear drives with circle arched profile in axial section requires the combined management of complex mathematical, geometric and manufacturing knowledge. In this paper has been presented an analysis of the relation between the post-sharpening of the cylindrical hob with circle arched profile in axial section and gear tooth surface error according to the functions determined by previous research work, that fits to the Dudás type ProMAT general mathematical model, which is suitable for the analysis of technological processes in manufacturing. During the research the extension of this method to any type of worm gear drives has been aspired.
\end{abstract}

Keywords: worm gear drive, hob, wear test, tooth surface.

\section{Introduction}

One of the highlighted research topics of the Worm Scientific School operating in the Difi-CAD Engineering Office, which has a cooperation agreement with the University of Miskolc, is the continuous further development of the production geometry of the worm gear drives (Dudás, 2016). The University of Miskolc previously carried out in joint research with Nagaoka University of Technology (Japan) through the Worm Scientific School on measuring tool wear with a CCD camera, which among other things also resulted in publications on grinding wheel profile wear (Varga et al., 2005).

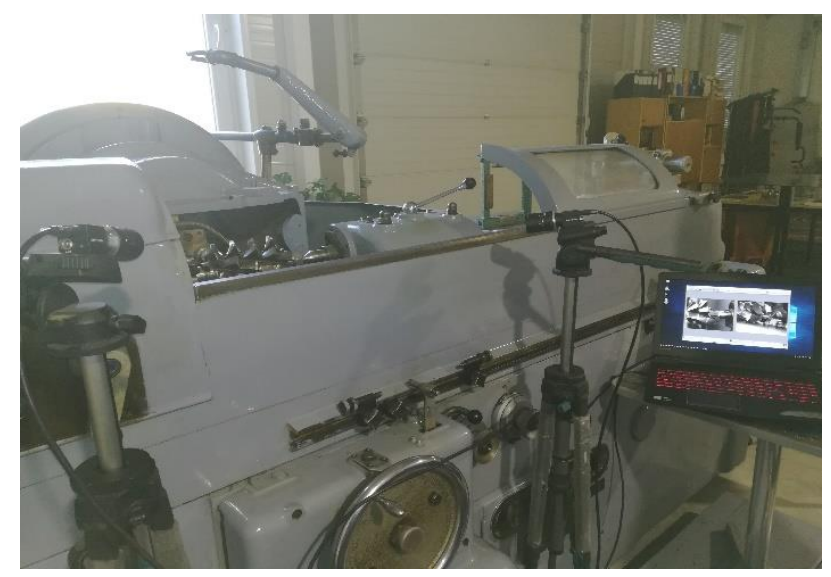

Figure 1. Positioning of CCD cameras to measure of the hob cutting edge in the DifiCAD Engineering Office.

The wearing of the cutting edge of the hob with circle arched profile in axial section as a spatial curve has been examined with two CCD cameras. The conditions for mathematically correct camera 
positioning have been determined by the Monge cuboid (Balajti, 2016) for ensuring the cutting edge curve of the hob with circle arched profile in axial section reconstructibility to set the tool into a predetermined position and to test measurement with two CCD cameras from a single position (Balajti et. al., 2020). The reconstruction of the cutting edge curve of the hob has been determined by method of descriptive geometry (Ábel et al., 2018).

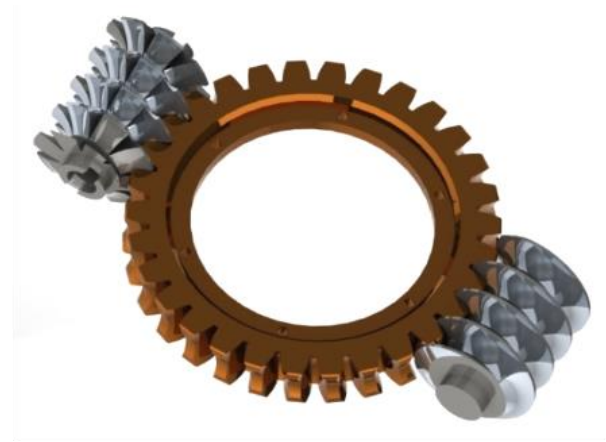

Figure 2. The circle arched profiled worm gear drive with the hob (Balajti, 2016).

The hob was designed from the cylindrical worm with a circular arc profile in the axial section, that geometrical parameters can be seen in Figure 3.

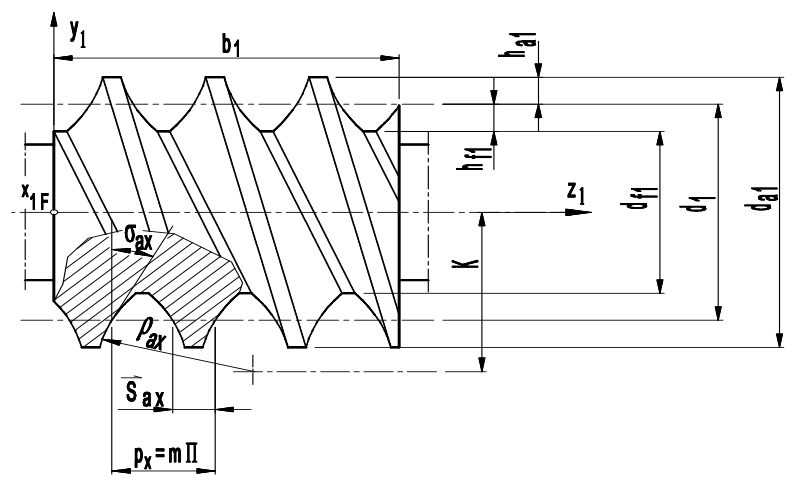

Figure 3. Geometrical parameters of the cylindrical worm with the circular arc profile in axial section (Dudás, 2004).

The tooth surface of the worm can be written in the following form in the $\mathrm{K}_{\mathrm{F} 1}\left(\mathrm{x}_{\mathrm{Fl}}, \mathrm{y}_{\mathrm{F} 1}, \mathrm{z}_{\mathrm{F} 1}\right)$ rotating coordinate system of the worm

$$
\mathbf{r}_{1 F}=\mathbf{r}_{1 F}(\eta, \vartheta)
$$

The $\mathbf{r}_{1 \mathrm{~F}}$ helical surface with circle arc profile in axial section in the $\mathrm{K}_{\mathrm{F} 1}\left(\mathrm{x}_{\mathrm{Fl}}, \mathrm{y}_{\mathrm{F} 1}, \mathrm{Z}_{\mathrm{F} 1}\right)$ rotating coordinate system with parameters from Figure 2 can be written in the following form

$$
\left.\begin{array}{l}
x_{1 \mathrm{~F}}=-\eta \cdot \sin \vartheta \cdot ; \\
y_{1 \mathrm{~F}}=\eta \cdot \cos \vartheta \cdot ; \\
z_{1 \mathrm{~F}}=\mathrm{p} \cdot \vartheta-\sqrt{\rho_{\mathrm{ax}}^{2}-(K-\eta)^{2}}
\end{array}\right\}
$$

As the hob is an expensive tool with complicated geometry, it is advisable to carry out repeated resharpening as many times as possible. Hob design requires an extremely strong background in manufacturing technology, production geometry and all areas mathematics (Felhö et. al., 2004). 
Factors such as wear, sharpening of tools may cause distortion of manufactured surfaces. Highprecision machining of the gear connected to the worm is required to achieve the specified good efficiency and low noise, among other things. The only tool that can be used for finishing machining on the gear tooth surface is one that covers the same surface as the worm connected to the gear (direct movement mapping).

The investigations have been developed with the support of the Dudás's kinematic mathematical model, of which a special improved case with the appropriate parameter selection refers to cylindrical worm gear drive pairs, as shown in Figure 4.

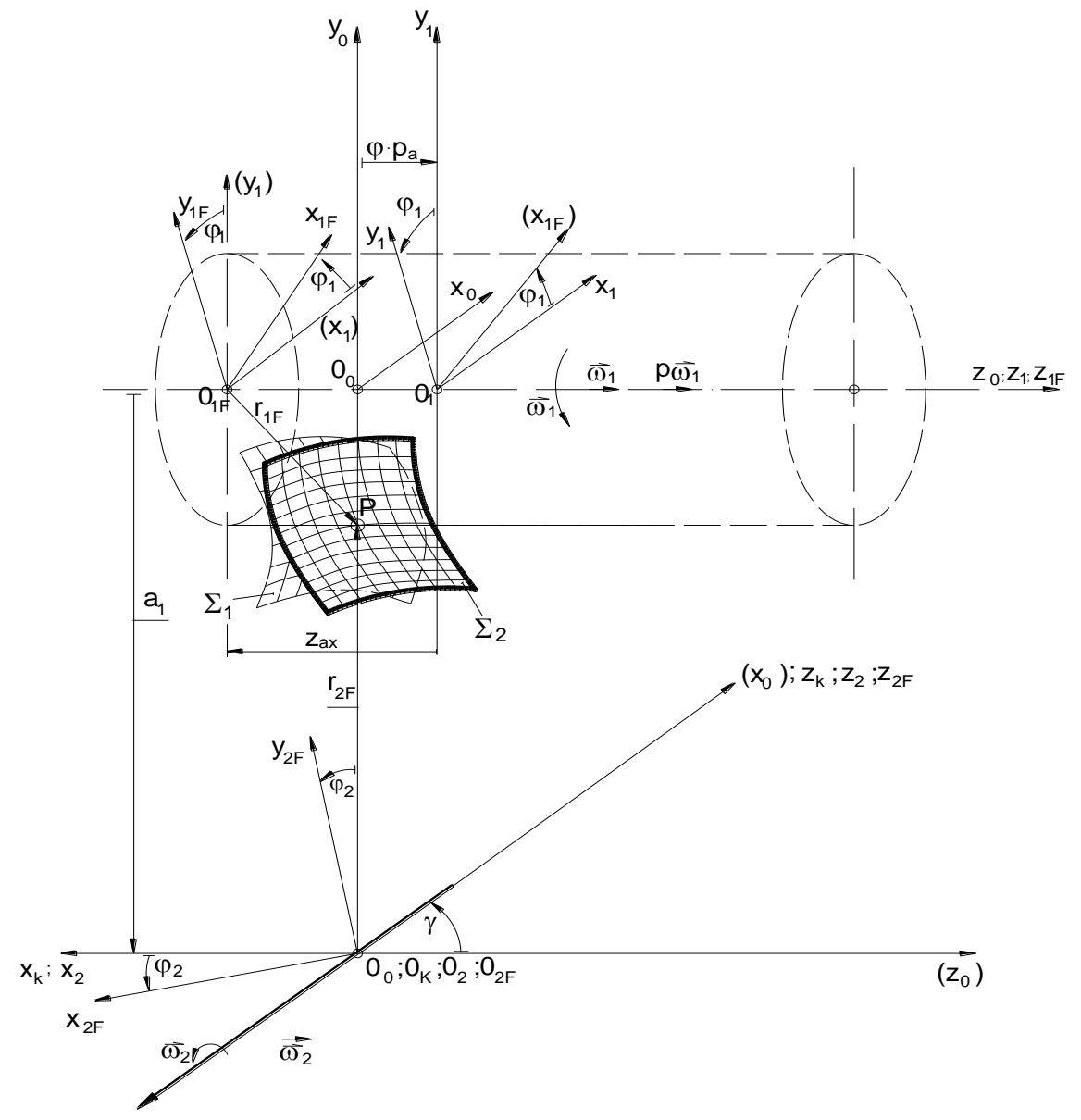

Figure 4. The applied coordinate systems in case helical worm gear drive with parameters $\alpha_{o}=0$, $c=0, p_{r}=0, \gamma \equiv \Sigma=-90^{\circ}$ (Balajti, 2007).

The cutting edges of the hob should be located on the tooth surfaces of the substituting worm. The substituting worm with the same tooth surface as the real worm has a larger addendum diameter and tooth thickness than the real worm, and they have common geometric axes, their diameter of reference cylinders $d_{m l}$ are identical, and their tooth surfaces on the same sided are coincident with the corresponding axial displacement. The teeth of the worm gear connected to the worm are determined by the teeth of the worm, since the contact tooth surfaces are mutually enveloping surfaces. 


\section{Problem}

During the production of worm gear, in order to achieve the required quality, the worm gear hob must be tested for wear and the cutting edge must be re-sharpened, which results in a decrease in the diameter of the hob leading to geometric deformation.

In the course of our previous research, the need to harmonize the relationships between the geometrical characteristics of the hob wear and the gear tooth surface affected by setting parameters has already been raised (Ábel et. al., 2021).

The cutting edges $V_{B}$ and $V_{J}$ of the hob can be obtained as an intersection of the backward grinded side surfaces $R_{B}$ and $R_{J}$, and the face surface $H$. Therefore, the back-machining and the technology of the processing should be carried out in such a way that the received edges $V_{B}$ and $V_{J}$ are on the tooth surface of the substituting worm, which is geometrically the same as the tooth surface of the real worm. The face surface of the hob is preferably a closed Archimedean worm surface, along which the tool is re-sharpened. Since the cutting edge V remains on the tooth surface of the same worm even after resharpening, it only shifts axially, the tool forms a tooth surface without profile distortion even after resharpening.

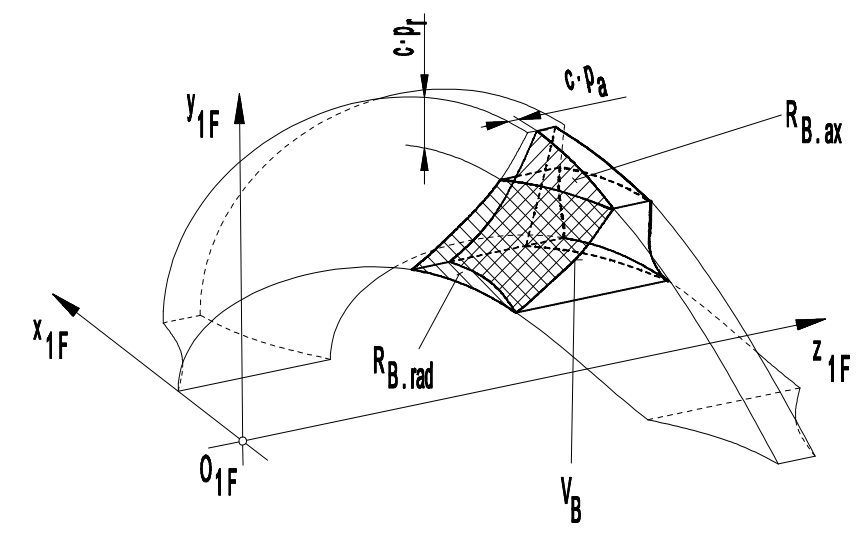

Figure 5. Cutting edge of the tooth of the hob in the $K_{I F}$ motion coordinate system (Dudás, 2004).

The face surface $\mathrm{H}$ of the hob is derived by the complex movement of a half-line perpendicular to the axis, which is a motion in axial direction with a screw parameter $p_{h}$ of the face-surface, and simultaneously a rotation about the axis. In the case of the right-handed hob the face surface $\mathrm{H}$ is lefthanded, where

$$
\gamma_{o h}=90^{\circ}-\gamma_{o}
$$

The equation of the face surface $\mathrm{H}$ can be written

$$
\left.\begin{array}{l}
x_{h}=-\eta \cdot \sin \left(\vartheta+\varphi_{o h}\right) ; \\
y_{h}=+\eta \cdot \cos \left(\vartheta+\varphi_{o h}\right) ; \\
z_{h}=-p_{h} \cdot \sin \left(\vartheta+\varphi_{o h}\right) ;
\end{array}\right\}
$$

where the lead parameter of the face surface $\mathrm{H}$ of the hob

$$
p_{h}=\frac{d_{01} \cdot \pi \cdot \operatorname{tg} \gamma_{o h}}{2 \cdot \pi}
$$


Making the appropriate substitutions

$$
-p_{h} \cdot\left(\vartheta+\varphi_{o h}\right)=p \cdot\left(\vartheta+\varphi_{o h}\right)-\sqrt{\rho_{a x}^{2}-(K-\eta)^{2}}+z_{a x}
$$

from which

$$
\varphi_{o h}=\frac{1}{p_{h}} \cdot \sqrt{\rho_{a x}^{2}-(K-\eta)^{2}}-\frac{p}{p_{h}} \cdot\left(\vartheta+\varphi_{o h}\right)-\vartheta-\frac{z_{a x}}{p_{h}} .
$$

Since the cutting edge $\mathrm{V}$ should remain on the substituting worm surface after re-sharpening, it forms a tooth on the wheel without profile distortion.

Its equation in the examined case can be written in the following form

$$
\left.\begin{array}{l}
x_{\mathrm{v}}=-\eta \cdot \sin \frac{\sqrt{\rho_{\mathrm{ax}}^{2}-(K-\eta)^{2}}-z_{\mathrm{ax}}}{p+p_{\mathrm{h}}} \\
y_{\mathrm{v}}=\eta \cdot \cos \frac{\sqrt{\rho_{\mathrm{ax}}^{2}-(K-\eta)^{2}}-z_{\mathrm{ax}}}{p+p_{\mathrm{h}}} \\
z_{\mathrm{v}}=-p_{\mathrm{h}} \cdot \frac{\sqrt{\rho_{\mathrm{ax}}^{2}-(K-\eta)^{2}}-z_{\mathrm{ax}}}{p+p_{\mathrm{h}}}
\end{array}\right\}
$$

However, in the case of radial rework, a radial dimensional change occurs after the tool has been resharpened. This results in a decrease in the centre distance $a$.

\section{Method}

The worm gear hob created from the worm is a suitable tool machining the worm gear tooth surface, therefore the examination of the contact area of the worm and mated gear leads to analysis of the manufacturing accuracy of the gear by the post-sharped hob.

The two elements of the drive pairs envelop each other in relative motion, their connection taking place along the contact line (Litvin et al., 1994).

The tooth surface $\Sigma_{2}$ of the gear can be produced as the covering surface of the worm starting from equation (2).

The coordinates of the normal vector $\mathbf{n}_{1 \mathrm{~F}}$ of the worm surface (2) can be calculated in the coordinate system $\mathrm{K}_{\mathrm{F} 1}\left(\mathrm{x}_{\mathrm{F} 1}, \mathrm{y}_{\mathrm{F} 1}, \mathrm{z}_{\mathrm{F} 1}\right)$ according to the partial derivate

$$
\left.\begin{array}{l}
\mathrm{n}_{1 \mathrm{Fx}}=-\eta \cdot \sin \vartheta \cdot \frac{\mathrm{K}-\eta}{\sqrt{\rho_{\mathrm{ax}}^{2}-(\mathrm{K}-\eta)^{2}}}+\mathrm{p} \cdot \cos \vartheta \\
\mathrm{n}_{1 \mathrm{Fy}}=\eta \cdot \cos \vartheta \cdot \frac{\mathrm{K}-\eta}{\sqrt{\rho_{\mathrm{ax}}^{2}-(\mathrm{K}-\eta)^{2}}}+\mathrm{p} \cdot \sin \vartheta \\
n_{1 \mathrm{Fz}}=\eta
\end{array}\right\}
$$

The $\mathbf{v}_{2 \mathrm{~F}}$ relative velocity vector between coordinate systems $\mathrm{K}_{1 \mathrm{~F}}\left(\mathrm{x}_{1 \mathrm{~F}}, \mathrm{y}_{1 \mathrm{~F}}, \mathrm{z}_{1 \mathrm{~F}}\right)$ of the worm and coordinate system $\mathrm{K}_{2 \mathrm{~F}}\left(\mathrm{x}_{2 \mathrm{~F}}, \mathrm{y}_{2 \mathrm{~F}}, \mathrm{Z}_{2 \mathrm{~F}}\right)$ of the mating gear can be calculated with the time derivative of the transformation matrix $\mathbf{M}_{2 \mathrm{~F}, 1 \mathrm{~F}}$

$$
\dot{\mathbf{r}}_{2 F}=\mathbf{v}_{2 \mathrm{~F}}^{(12)}=\frac{d}{d t}\left(\mathbf{M}_{2 F, l F} \cdot \mathbf{r}_{1 \mathrm{~F}}\right)=\frac{d \mathbf{M}_{2 F, I F}}{d t} \cdot \mathbf{r}_{1 \mathrm{~F}}
$$

The $\mathbf{v}_{1 \mathrm{~F}}$ relative velocity vector between the worm and the mating gear can be written 
where

$$
\mathbf{v}_{1 \mathrm{~F}}^{(12)}=\mathbf{M}_{1 F, 2 F} \frac{d}{d t}\left(\mathbf{M}_{2 F, 1 F} \cdot \mathbf{r}_{1 \mathrm{~F}}\right)=\mathbf{M}_{1 F, 2 F} \cdot \frac{d \mathbf{M}_{2 F, 1 F}}{d t} \cdot \mathbf{r}_{1 \mathrm{~F}}
$$

$$
\mathbf{P}_{1 a}=\mathbf{M}_{1 F, 2 F} \cdot \frac{d \mathbf{M}_{2 F, l F}}{d t}
$$

the "kinematic transformer" matrix.

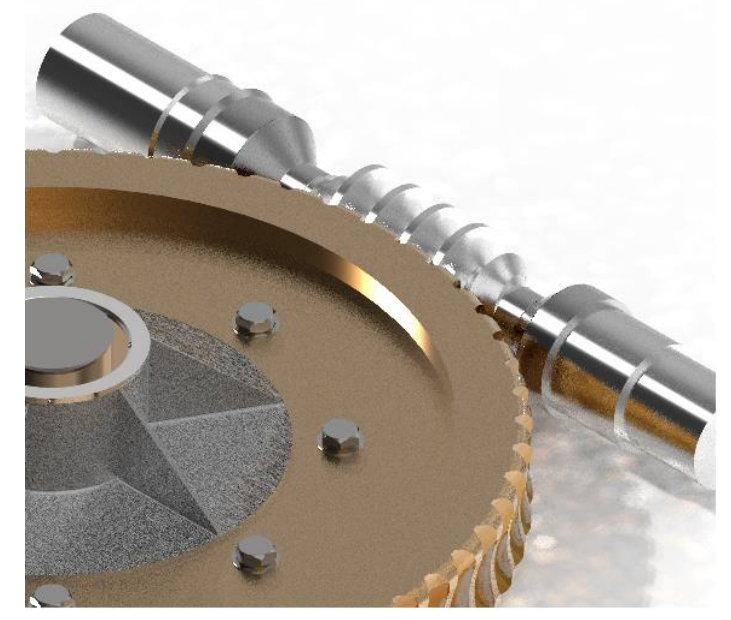

Figure 6. The bearing pattern marked with white chalk powder.

The values parameters $(\eta, \vartheta)$ of the worm surface should be a function of parameter $u$. The equation of the contact lines is described according to the first formula of connection with one fixed motion parameter $\varphi_{1}$ in the following function relation

$$
\mathrm{f}\left(\eta(\mathrm{u}), \vartheta(\mathrm{u}), \varphi_{1}\right)=\mathrm{f}\left(\mathrm{u}, \varphi_{1}\right)=\mathbf{n}_{1 \mathrm{~F}} \cdot \mathbf{v}_{1 \mathrm{~F}}=0
$$

The tooth surface $\Sigma_{2}$ of the worm wheel can be produced as the covering surface of the instantaneous contact lines written in the coordinate system $\mathrm{K}_{2 \mathrm{~F}}$ fixed to the worm wheel

$$
\left.\begin{array}{l}
f\left(\eta, \vartheta, \varphi_{1}\right)=0 \\
\mathbf{r}_{1 \mathrm{~F}}=\mathbf{r}_{1 \mathrm{~F}}(\eta, \vartheta) \\
\mathbf{r}_{2 \mathrm{~F}_{-} \text {gear }}=\mathbf{M}_{2 \mathrm{~F}, 1 \mathrm{~F}_{\text {arc }}} \cdot \mathbf{r}_{1 \mathrm{~F}}
\end{array}\right\}
$$

\section{Result}

The coordinates of position vector $\mathbf{r}_{2 \mathrm{~F}}$ pointing to the tooth surface $\Sigma_{2}$ of the gear in the $\mathrm{K}_{2 \mathrm{~F}}$ fixed coordinate system to the worm wheel are

$$
\left.\begin{array}{c}
\mathrm{x}_{2 \mathrm{~F}_{-} \mathrm{gear}}=\sin \varphi_{1} \cdot \sin \varphi_{2} \cdot \eta \cdot \sin \vartheta-\cos \varphi_{1} \cdot \sin \varphi_{2} \cdot \eta \cdot \cos \vartheta \\
-\cos \varphi_{2} \cdot\left(p_{a} \cdot \vartheta-\sqrt{\rho_{\mathrm{ax}}^{2}-(\mathrm{K}-\eta)^{2}}\right)-(a+\Delta a) \cdot \sin \varphi_{2} \\
\mathrm{y}_{2 \mathrm{~F}_{-} \text {gear }}=\sin \varphi_{1} \cdot \cos \varphi_{2} \cdot \eta \cdot \sin \vartheta+\cos \varphi_{1} \cdot \cos \varphi_{2} \cdot \eta \cdot \cos \vartheta \\
-\sin \varphi_{2} \cdot\left(p_{a} \cdot \vartheta-\sqrt{\rho_{\mathrm{ax}}^{2}-(\mathrm{K}-\eta)^{2}}\right)-(a+\Delta a) \cdot \cos \varphi_{2} \\
\mathrm{z}_{2 \mathrm{~F}_{-} \text {gear }}=-\cos \varphi_{1} \cdot \eta \cdot \sin \vartheta-\sin \varphi_{1} \cdot \eta \cdot \cos \vartheta
\end{array}\right\}
$$


The result shows the changing in $\mathrm{x}_{2 \mathrm{~F}_{-} \text {gear }}$ and $\mathrm{y}_{2 \mathrm{~F}_{-} \text {gear }}$ coordinates, so the analysis have been done in its plane.

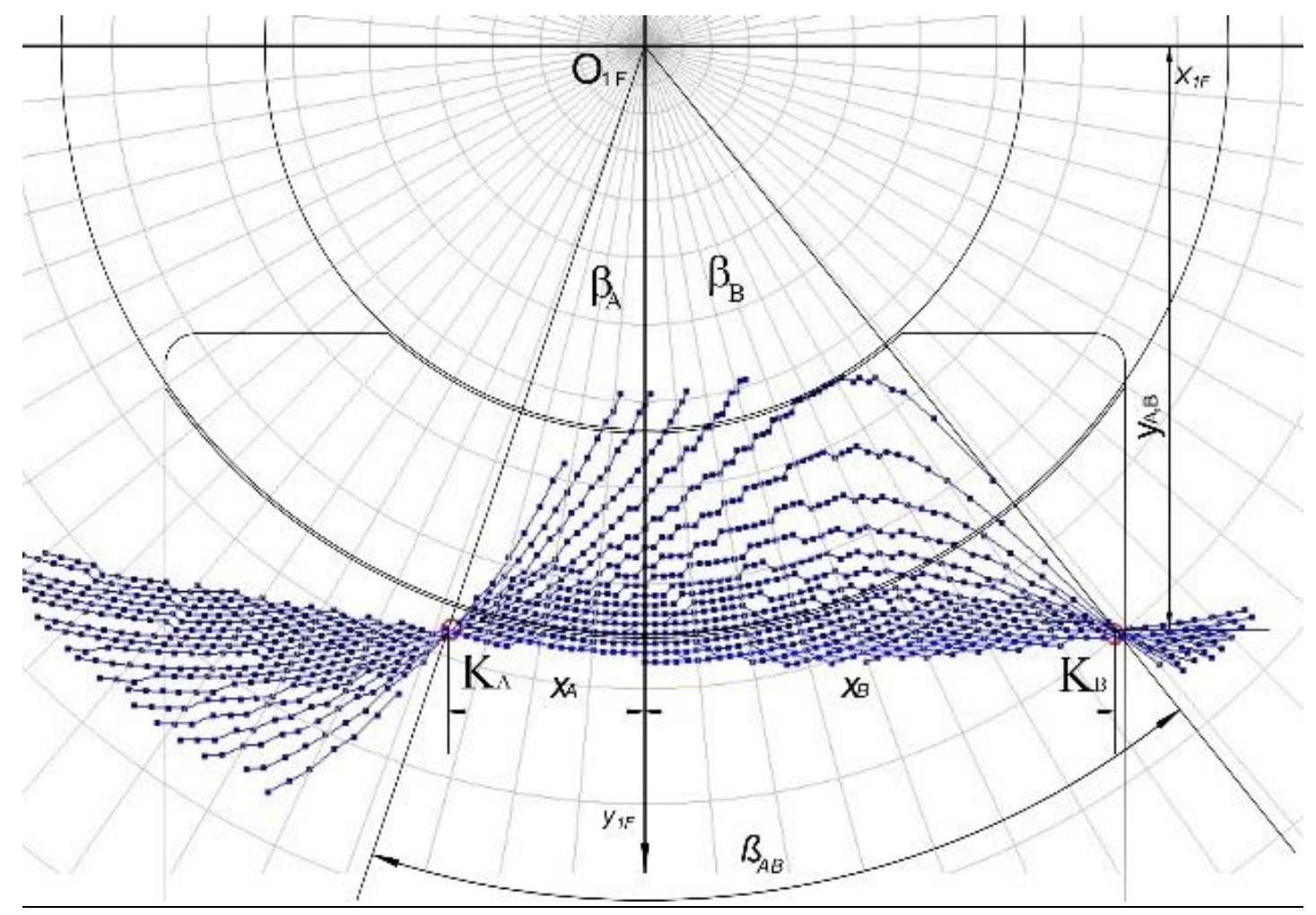

Figure 7. Contact lines in the plane [( $\left.\left.x_{2}\right),\left(y_{2}\right)\right]$ with $K_{A}$ and $K_{B}$ knots, based on a computer program developed by us

In the case of a designed and manufactured worm with data $z_{l}=3, m=12.5, \gamma_{0}=21^{\circ} 2^{\prime} 15^{\prime \prime}, \rho_{a x}=50, \bar{S}_{a l}=10$ to set addendum on tooth chord, $\bar{S}_{n l}=13_{-0.125}^{+0.0}$ size of worm tooth chord, $a=280, d_{01}=97,5$, $H=117,809722, \delta_{a x}=24^{\circ} 31^{\prime} 10^{\prime}, z_{2}=35, F_{r l}= \pm 0,017, f_{p l}= \pm 0,016, f_{r}= \pm 0,018, f_{f}=0,08$ [2] the position contact points are illustrated in Figure 7.

The principle of operation of our computer program for the production of contact lines is that the program calculates the implicit system of equations required to start the procedure from the data passed as input.

Based on the input data, the scope of the study is delimited, so according to the boundary conditions, the search procedure calculates the contact points for the given case. It converts the resulting set of points into an ordered group of points in a contact curve.

The reference parameters of the gear tooth surface $\beta_{A B}(a)$ and $X_{A}(a)$ as a functions of the changing centre distance $a$ can be seen in Figure 8. Based on this function, changing surface of the gear tooth has been become manageable depending on the hob wear. 


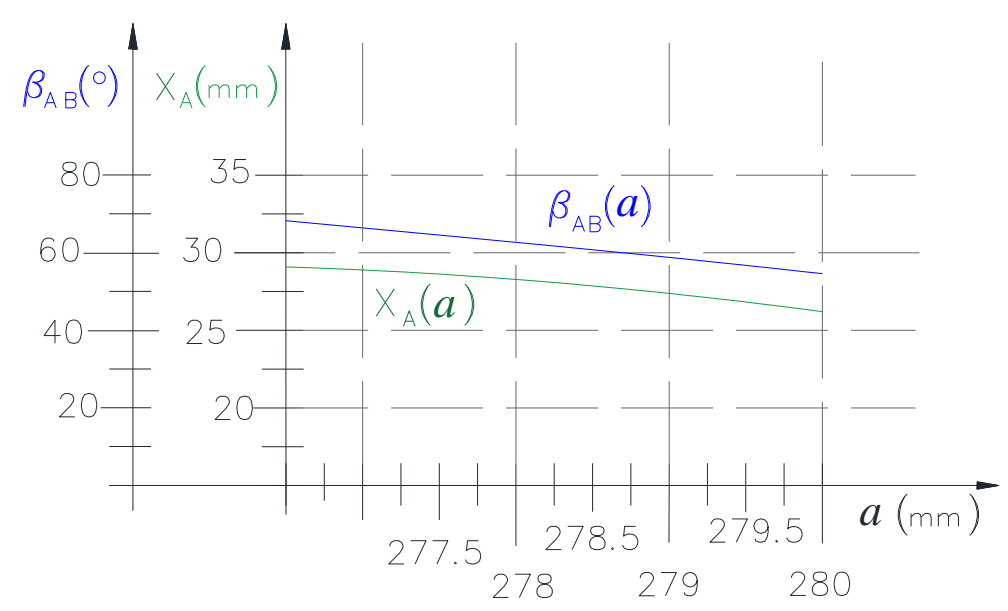

Figure 8. Changes of the knot $X_{A}$ position and the size of the centre angle $\beta_{A B}$ depending on the a centre distance.

\section{Conclusion}

This research examines the relationships between the gear accuracy manufactured by re-sharpened hob in case a cylindrical worm gear hob with circle arched profile in axial section. The re-sharpening of the hob manufactured with special tooth side surfaces after wear results in a reduction in the diameter of axes, which cause the change in geometric conditions. The study was discussed on the principle of this reciprocal, two-parameter enveloping. The function description of the adjustment parameters of the postsharpened hob, for all cylindrical hobs with circle arc profile in axial section has been developed to support production accuracy of the mated gear. At the same time, the relation between the geometrical parameters of the re-sharpened worm gear hob and the changing of the centre angle of the knots of contact zone has been given as a function. The limit of re-sharpening of the worm gear hob is related to the decrease in axes distance, which was explored at this stage of the research as function. The general relationships between the post-sharpening adjustment parameters and the gear tooth surface changing in the present study serve to expand the innovative engineering tools for continuity of production.

\section{References}

[1] Dudás, I. (2016). The extension of the general mathematical model developed for helicoid surfaces to the whole system of manufacturing technology and production geometry (ProMAT). The International Journal of Advanced Manufacturing Technology, 86(5-8), 1557-1572. https://doi.org/10.1007/s00170-015-8233-5

[2] Varga, Gy., Balajti, Zs., Dudás, I. (2005). Advantages of CCD Camera Measurements for Profile and Wear of Cutting Tools, Journal of Physics: Conference Series, 13, 159-162. https://doi.org/10.1088/1472-6596/13/1/037

[3] Balajti Zs. (2016):: Production Geometric Development of Meshing Surface Pairs, With Descriptive Geometric Application. Habilitation Thesis Book. Miskolc. p. 78.

[4] Balajti, Zs., Ábel, J. (2020). Edge geometry test method with correctly positioned CCD cameras for production geometrical development of a worm gear hob with arched profile. Procedia Manufacturing 51, 365-372. https://doi.org/10.1016/j.promfg.2020.10.052 
[5] Ábel, J., Balajti, Zs. (2018). Examination of Tool Wear of Teeth with the Method of Descriptive Geometry (in Hungarian), XXVI. Nemzetközi Gépészeti Konferencia, 26-29 of April 2018. pp. 12-15.

[6] Dudás, I. (2004). The Theory \& Practice of Worm Gear Drives. Kogan Page US. Sterling. USA.

[7] Felhő, Cs., Szentesi, A., Tóth, G. (2004). Geometrical Dimensioning of Worm Drives. Proceeding of the 11th International Conference on Tools: ICT-2004. Miskolc, Hungary, University of Miskolc, pp. 177-182.

[8] Balajti, Zs. (2007). Development of production geometry of kinematical drive pairs. $\mathrm{PhD}$ dissertation (in Hungarian), Miskolc, Hungary. p. 126.

[9] Ábel, J., Balajti, Zs. (2021). Examination for post-sharpening adjustment of cutting edge of a worm gear hob with circle arched profile in axial section.. Procedia Manufacturing (under appearance)

[10] Litvin, F. L., Fuentes, A. (1994). Gear Geometry and Applied Theory. Englewood Cliffs. Prentice Hall. NJ. 